\title{
Garantia de direitos e burocracias estatais: mediadores universitários, protagonistas quilombolas e a tradição em disputa
}

Access to rights and the state bureaucracy: academic mediators, quilombola protagonism and tradition in dispute

Luiza Aragon Ovalle*

* Universidade Federal Fluminense - Niterói, RJ, Brasil Doutoranda em Antropologia (bolsista CNPq) luizaaragon@gmail.com

Yolanda Gaffrée Ribeiro**

** Universidade Federal do Rio de Janeiro - Rio de Janeiro, RJ, Brasil gr.yolanda@gmail.com 


\title{
Resumo
}

Discutimos o lugar de mediadores na captação e no direcionamento de recursos para comunidades remanescentes de quilombos em duas chamadas públicas, veiculadas pela Delegação da União Europeia no Brasil e pelo Estado brasileiro, onde nossa participação como antropólogas foi requisitada pelas lideranças comunitárias do Quilombo Sacopã, território localizado na cidade do Rio de Janeiro. Tanto a referida agência de fomento internacional quanto a Secretaria Especial de Políticas de Promoção da Igualdade Racial (Seppir) buscavam propostas voltadas à defesa dos direitos humanos no Brasil. Refletimos sobre a captação de recursos através de projetos, na interface entre o acesso a direitos e a moldagem da tradição através das relações políticas com Estados nacionais e suas burocracias, que informam as relações institucionais com esses grupos. A conformação de tradições através dos vínculos sociais que as possibilitam também constituem uma competição com o Estado pela sua definição para além dos moldes generalizados e padronizados assim impostos.

Palavras-chave: burocracia; quilombos; tecnologias sociais; Estado.

\begin{abstract}
We discuss the place of mediators in acquiring and directing resources to comunidades remanescentes de quilombos in the case of two public calls, one by the European Union and the other by the Brazilian state, in which our participation was required by leaderships of Quilombo Sacopã, territory located in Rio de Janeiro city. Both the referred international funding agency and the Special Office for the Promotion of Racial Equality (Seppir) were aiming at propositions for the defense of human rights in Brazil. We discuss the way to give direction to these resources through projects, talking about the access to rights and the shaping of tradition through political relations with national states and its bureaucracies, which inform institutional relations with these groups. Shaping traditions through social bonds which make them possible also constitute a competition with the state for the definition beyond general standards, imposed by these processes.
\end{abstract}

Keywords: bureaucracy; quilombos; social technologies; state. 


\section{Introdução}

Este artigo tem como objetivo levantar questões sobre a redação de um projeto em conjunto com as lideranças da comunidade quilombola Sacopã, para viabilizar o envio de uma proposta à Delegação da União Europeia no Brasil, na ocasião da chamada pública divulgada em abril de 2015. Localizado no valorizado bairro da Lagoa Rodrigo de Freitas, zona sul da cidade do Rio de Janeiro, o quilombo foi nosso parceiro privilegiado na elaboração desse projeto.

A chegada da família Pinto à região remonta à década de 1920, período em que seu patriarca, Manoel Pinto, trabalhou nas obras de abertura da Ladeira Sacopã. A permanência da família nesse espaço acompanha várias transformações urbanísticas pelas quais passa a cidade do Rio de Janeiro e que promovem, por sua vez, mudanças significativas quanto ao perfil das moradias e da população do bairro, cada vez mais composta de residências luxuosas e "vizinhos poderosos".

Os esforços de permanência no local se dão, assim, em primeiro momento, por meio do processo de usucapião, iniciado em 1975. Desde então, a família recorre e responde a diversos processos judiciais que têm como cerne a disputa em torno de direitos territoriais e seus usos, mantendo as incertezas vividas quanto às possibilidades de garantia do território.

Ainda na década de 1980, Luiz Sacopã e sua irmã, Tia Neném, dão início a uma importante atividade no local: a roda de samba com feijoada que reúne artistas do mundo do samba como Beth Carvalho e Jorge Aragão, além de políticos, militantes dos movimentos negros, admiradores desse estilo musical, entre outros. Esse espaço de confraternização se torna, assim, um mecanismo de integração da família com a vizinhança, bem como com diversos circuitos políticos e institucionais da cidade, os quais viabilizam mecanismos de integração em torno de uma causa central: a permanência da família em suas terras. Por outro lado, a pressão de alguns moradores vizinhos, por meio de sucessivas liminares na justiça, com o objetivo de pôr fim ao samba com feijoada, assim como às atividades comerciais que contribuem para o sustento da família, como a oficina mecânica e a venda de quentinhas, se faz presente e frequentemente eficaz.

Após a morte de Tia Neném, que tinha um grande papel na família e na vida política do lugar, seu irmão, Luiz Sacopã, tomou a frente e imprimiu seu 
próprio estilo de administração de conflitos. Hoje, é o presidente da Associação de Comunidades Quilombolas do Estado do Rio de Janeiro (Acquilerj) e suas narrativas revelam as tensões particulares do seu cotidiano. Quase todos os dias precisa se deslocar até o Ministério Público, ou até o Incra, ou à Fundação Palmares, buscando alianças para mover os processos sobre o próprio território e articulando financiamento para encontros de quilombolas. Aproveitar as oportunidades de tornar visíveis as suas causas, estar sempre atento e disposto a articular densas narrativas sobre cada quilombo que representa são requisitos necessários para se fazer conhecer e reconhecer enquanto sujeito de direito.

A interlocução com a família Sacopã teve início há mais de uma década, através de pesquisadores do Núcleo Fluminense de Estudos e Pesquisas (Nufep/UFF) e do Núcleo de Pesquisas sobre Práticas e Instituições Jurídicas (Nupij/UFF). Ambos os núcleos da Universidade Federal Fluminense desenvolvem pesquisas e atuam na construção de direitos de cidadania entre seus interlocutores, por exemplo, o Quilombo da Marambaia, ${ }^{1}$ a comunidade tradicional do Morro das Andorinhas e dos pescadores artesanais de Itaipu, ${ }^{2}$ através da produção de peças técnicas que contribuam a favor dessas populações em processos judiciais (como no caso do processo de titulação do território do Sacopã), envolvidas na produção de tecnologias sociais, termo que será um dos eixos discutidos no presente artigo.

Buscamos compreender, mais do que o lugar de antropólogos como especialistas, sua atuação enquanto mediadores em processos de reconhecimento da diferença no espaço público (Ribeiro, 2017). Nesse sentido, consideramos a noção de mediação social menos em sua acepção genérica e chamamos a atenção para as especificidades na atuação desses agentes (Neves, 2008). Assim, propomos reflexões, ao mesmo tempo em que influenciamos as condições de competição estabelecidas por esses aparatos burocráticos, a saber, os editais que convidam ao envio de projetos de curto e médio prazo.

1 A interlocução com os quilombolas do Sacopã, assim, remete ao contato anterior de pesquisa e construção de peças jurídicas com os quilombolas da Marambaia que apresentaram os pesquisadores da UFF, notadamente do Departamento de Antropologia, ligados ao Nufep, e também da Faculdade de Direito, com o Nupij. A Ilha da Marambaia é localizada no município de Mangaratiba, no estado do Rio de Janeiro.

2 Localizado na região oceânica da cidade de Niterói, região metropolitana do estado do Rio de Janeiro. 


\section{Quilombos no Brasil}

As mobilizações em torno de direitos, ao longo da década de 1990, orientadas para a aplicação do artigo 68 do Ato das Disposições Constitucionais Transitórias (ADCT) da Constituição de $1988,{ }^{3}$ que garante direitos territoriais às denominadas comunidades remanescentes de quilombos, permitirá um lento e conflituoso processo de ressignificação desta categoria. Nesse contexto, leva à produção de instrumentos legislativos nas esferas estaduais e em âmbito federal para a regulamentação dos territórios quilombolas. São criados, assim, diversos instrumentos jurídicos e administrativos para orientar os procedimentos de delimitação, demarcação e regularização fundiária dessas comunidades, os quais precisam acompanhar diferentes temporalidades de cada etapa burocrática, compondo os processos de reconhecimento em curso.

A reinterpretação do conceito de quilombo e a inclusão do termo como atributiva de direitos estão articuladas, ainda, à participação de movimentos de luta pela terra, assim como à atuação de especialistas, especialmente antropólogos. A atuação de diversos intelectuais no âmbito dos movimentos negros permite a construção de repertórios associados à afirmação de uma negritude no espaço público, assim como de valorização de uma identidade afro-brasileira e à reparação histórica.

Esse processo inclui, ainda, a participação de funcionários de agências governamentais, responsáveis pelos processos de regularização fundiária, pesquisadores que aparecem na condição de especialistas, assim como os novos sujeitos de direitos, inseridos nos tempos da política, da justiça e da administração pública. Dentro desse quadro, são mobilizados recursos e dispositivos de caráter tanto institucional quanto simbólico na articulação de redes, onde são sustentadas alianças políticas e institucionais diversas. Elas permitem dar certa visibilidade às demandas dos grupos, ainda que nem sempre a titulação definitiva de seus territórios, pleito principal em boa parte dos casos, esteja efetivada.

3 O texto do artigo constitucional diz que: "Aos remanescentes das comunidades dos quilombos que estejam ocupando suas terras é reconhecida a propriedade definitiva, devendo o Estado emitir-lhes os títulos respectivos" (Brasil, 1988, art. 68, p. 46). 
Ao longo da década de 1990 e dos anos 2000, são criados diversos organismos de representação em nível nacional e estadual, tal como a Comissão Nacional Provisória de Articulação das Comunidades Negras Rurais Quilombolas (CNACNRQ), em 1996, e a Associação de Comunidades Quilombolas do Estado do Rio de Janeiro (Acquilerj), em 2003, por exemplo. Essa construção de redes de mobilização política variadas contempla a diversidade de situações que aparecem sob a designação mais ampla de comunidades remanescentes de quilombos, no Brasil.

Como chama atenção O'Dwyer (2007, 2010), a atuação de antropólogos em meio a esses processos se dá principalmente através da elaboração de laudos antropológicos (relatórios de pesquisa). Remonta, por sua vez, à participação desses profissionais que, desde a criação em 1996 do Grupo de Trabalho Terras de Quilombos, da Associação Brasileira de Antropologia (ABA), mantêm diálogos com diversas instâncias governamentais, no âmbito do Congresso Nacional e casas legislativas, assim como com o Ministério Público Federal, entre outros.

Até 2003, a Fundação Cultural Palmares (FCP), na esfera federal, era a principal responsável pela titulação das terras quilombolas, incluindo a identificação e delimitação dos territórios. A elaboração do decreto $n^{\circ} 4.887$, de 20 de novembro de 2003, do governo federal (Brasil, 2003) prevê diversas regulamentações e procedimentos para identificação, reconhecimento, delimitação e titulação das terras ocupadas pelos remanescentes de quilombos de que trata o artigo 68 do ADCT. Nesse sentido, é atribuída ao Incra a responsabilidade de titular os territórios quilombolas localizados em terras públicas ou que incidam em áreas de particulares, de acordo com o referido decreto. Aos estados e municípios, por sua vez, cabe a emissão dos títulos às comunidades quilombolas localizadas em terras de domínio estadual e municipal, respectivamente.

A emergência de uma gramática multicultural contemporânea (Taylor, 2009) de alcance global adquire diferentes contornos de acordo com as tradições políticas e gramáticas jurídicas locais. No caso do Brasil, as demandas por direitos de cidadania se associam à construção de identidades diferenciadas (Mota, 2014), em um processo de construção legal de identidades (Lobão, 2010) vinculado à elaboração de instrumentos normativos e diretrizes internacionais, as quais são lidas e apropriadas pelos atores no espaço público de modo diverso. A Convenção 169 da Organização Internacional do Trabalho (OIT), da 
qual o Brasil é signatário, ${ }^{4}$ está inserida no debate que contribuiu para a elaboração do decreto $\mathrm{n}^{\circ} 4.887 / 2003$, que regulamenta o processo de identificação e regulamentação dos territórios quilombolas e que incorpora em seu texto, por exemplo, o critério de autoatribuição $0^{5}$ identitária para o reconhecimento oficial de tais grupos.

Entre as etapas administrativas no âmbito da identificação, delimitação e titulação dos territórios quilombolas, por meio do decreto $n^{\circ} 4.887 / 2003$, está o Relatório Técnico de Identificação e Delimitação (RTID). Nesse processo de reconhecimento oficial, a produção de peças técnicas ou relatórios, também chamadas laudos histórico-antropológicos, é uma etapa necessária e cronologicamente posterior à autoatribuição, cuja importância não substitui a interação com equipes multidisciplinares envolvidas nos procedimentos jurídicos e burocráticos da titulação territorial, as quais contemplam especialistas entre os quais, além de antropólogos, figuram geógrafos, cartógrafos, agrônomos, historiadores, etc. (Leitão, 2006).

Dessa forma, as demandas por direitos vinculadas à construção de identidades coletivas, no caso, a de remanescentes de quilombos, se associam às possibilidades de consolidação de direitos constitucionais, e abrem espaço para a formulação de políticas públicas direcionadas, estabelecendo tanto redes de cooperação como formas de competição por recursos escassos. Nesse sentido, o projeto enviado para atender à chamada da Delegação da União Europeia no Brasil teve como objetivo angariar recursos que contribuíssem para o quilombo em atividades que sustentem diferenças, reconhecidas como diacríticos identitários no espaço público, bem como para a produção de conhecimento acadêmico acerca desses processos. No presente caso, nos comprometemos com a produção de peças jurídicas, arrecadação de recursos e implementação de projetos para (re)produção da diferença e garantia de direitos.

Essas diferenças não existem enquanto categoria frigorificada (O'Dwyer, 2007), mas são encarnadas nas pessoas e nos dispositivos (Thévenot, 1997)

4 A Convenção 169 da Organização Internacional do Trabalho, sobre povos indígenas e tribais, foi adotada em Genebra no ano de 1989 e ratificada, no Brasil, em 2002.

5 É interessante notar que tanto no texto da Convenção 169 da OIT como no do decreto $\mathrm{n}^{\circ} 4.887 / 2003$, o critério de autoatribuição pode ser associado à influência de uma "perspectiva" antropológica adotada, em que o conceito de etnicidade como construção de fronteiras identitárias estabelecidas pelos próprios grupos é relevante. 
através de seus posicionamentos no mundo. $\mathrm{O}$ eixo argumentativo, assim, põe sob descrição as formas como a tradição se apresenta na trajetória dos quilombolas e demais atores envolvidos nessa rede. Propomos refletir sobre como a antropologia disputa seu próprio lugar na produção de um conhecimento implicado na iniciativa de produção de tecnologias sociais, no diálogo com setores da administração pública e com outros campos de conhecimento, tais como o direito, a geografia e a biologia.

\section{Uma narrativa cronológica: trajetórias em perspectiva na construção de acordos contextuais}

Sete dias antes do prazo final para o envio do projeto à Delegação da União Europeia no Brasil, Fabio Mota, nosso orientador, recebeu uma ligação da liderança do Quilombo Sacopã. Um de seus muitos contatos, que não conhecemos, lhe falou sobre como o edital então aberto era adequado para o quilombo e como havia uma grande possibilidade de ganhar. Quando a família tentou escrever o projeto sozinha, uma antropóloga que frequenta o lugar há muitos anos, amiga da família, avisou que a burocracia dessa agência europeia supranacional era extensa e complicada demais para que o envio fosse feito sem ajuda. De início, tentaram sustentar sua autonomia sem nossa mediação e, já sem muita esperança, acreditaram que não faria mal nos incluir.

Não vimos o convite como um caso perdido, até porque nos foi apresentado naquele momento como uma boa oportunidade, e embora a urgência nos desse a impressão de que muitas etapas burocráticas poderiam inviabilizar o seu envio, reunimos todos os nossos recursos e paramos todas as outras atividades para investir nessa abertura de diálogo e mediação. Foram dez pessoas, entre pós-graduandos e estagiários do Nufep/UFF, que tocaram o projeto. Acostumados à burocracia necessária para atender a chamadas do CNPq e da Faperj, agências de fomento estatais, de caráter acadêmico familiar para nós, nos empenhamos em formular um projeto com qualidades acadêmicas que dessem respaldo às atividades culturais, políticas e econômicas do quilombo. Dessa forma, tanto os quilombolas quanto os pesquisadores seriam contemplados pelos recursos do edital, financiando tanto nossas pesquisas quanto a vida no quilombo. 
Nossa primeira surpresa, ao ler o edital, foi o fato de os quilombolas acreditarem que poderiam enviá-lo sozinhos. A burocracia, logo à primeira vista, nos pareceu muito maior do que a da Faperj, conhecida na academia por ser a agência de fomento mais burocratizada e cartorial dentre aquelas que investem no estado do Rio de Janeiro. As exigências de sua prestação de contas, seus orçamentos e etapas de envio on-line pressupõem a inscrição do pesquisador-coordenador num sistema de identificação próprio, cuja tecnologia não permite a alimentação de informações através de outras plataformas onde os professores universitários e pós-graduandos já investem um tempo considerável na sua apresentação profissional. Em seu significado ambivalente, além de demonstrar status e a abertura para novos laços profissionais, é um mecanismo de vigilância entre colegas os quais, a partir disso, medem os recursos que o grupo como um todo é capaz de mobilizar para a universidade, seus projetos e seus respectivos alunos.

Assim, a Delegação da União Europeia no Brasil utilizava sua própria plataforma de identificação, a qual, à semelhança da Faperj, exigia que todos os dados fossem compilados novamente. Essa primeira plataforma, chamada Pador, era separada de outra plataforma onde o projeto referente a esse edital específico deveria ser anexado, a Prospect. Nossas duas fontes fundamentais de estresse foram os arquivos que, em conjunto, eram o edital e as tabelas a serem alimentadas na plataforma Pador. Acostumados à burocracia acadêmica, nos surpreendemos com a diferença entre a organização requisitada no edital (e seus extensos documentos explicativos auxiliares) e aquela que nos era exigida na Pador. As categorias de classificação para a instituição que atendia à chamada, propondo o projeto, nos causaram um estranhamento inicial quando as vimos no edital, e um novo estranhamento quando fizemos um perfil de teste para ter acesso às tabelas que precisaríamos preencher na Pador.

Em primeiro lugar, as instruções e esclarecimentos na plataforma estão todos em inglês, embora os arquivos possam ser mandados em português. Mesmo em se tratando de um quilombo urbano, onde os moradores possuem uma inserção no mercado de trabalho que muitas vezes exige o domínio da língua inglesa para subir na carreira, são poucos os moradores que têm contato com uma língua estrangeira. Com isso, o objetivo inclusivo do edital, de promover o protagonismo de proponentes da sociedade civil, fica comprometido. 
A plataforma de identificação possui, ao todo, dez páginas repletas de requerimentos de dados, documentos e anexos, separadas por temas que ajudavam a classificar o proponente, o projeto e as instituições de apoio. Para abrir a página com as tabelas seguintes, era necessário preencher todos os campos na página anterior. Algumas vezes, era necessário anexar documentos de teste para passar à página seguinte, o que nos revelava, por vezes, trabalhos extensos, como é o caso da tabela de prestação de contas da instituição como um todo nos últimos três anos. O processo completo de inscrição é bloqueado e cancelado quando o proponente passa mais de 90 minutos efetuando o preenchimento, no entanto, não sabemos de antemão quais são as exigências de cada página, muitas vezes extensas. Sem a experiência burocrática que nos levou a gerar um perfil de teste e fazer um levantamento extenso que organizasse as exigências da plataforma de identificação, seria impossível completar o registro do perfil, seja da universidade, seja da associação quilombola que desejávamos, desde o começo, inscrever como proponente.

Outro obstáculo é de cunho classificatório, que ao caracterizar o proponente como público, privado ou associativo dificulta a identificação da Associação Cultural Quilombo Sacopã (ACQS) como uma comunidade tradicional na plataforma de identificação, em contraste com o edital, o qual elencava, entre os possíveis públicos-alvo, as comunidades quilombolas e indígenas, curiosamente numa categoria separada das populações afrodescendentes. ${ }^{6}$

\section{Seguindo o edital}

Os processos que Taylor (2009) define como de doutrinas constitucionais de revisão jurídica estão no cerne da confecção de uma gramática multicultural contemporânea. Princípios tais como o de direitos humanos ou de dignidade da pessoa humana orientam a formulação de diretrizes internacionais, através de órgãos tais como a ONU, a Unesco, a OIT, e orientam a formulação de pactos "regionais" que não se configuram sem tensão. Não à toa, a presente chamada

6 É interessante pensar nas consequências disso, uma vez que as ONGs (que normalmente são as entidades proponentes) são formadas, muitas vezes, por membros dos movimentos negros urbanos, pessoas diferentes daquelas que habitam, por exemplo, quilombos rurais. 
da Delegação da União Europeia no Brasil se enquadra em uma proposta mais ampla de "defesa dos direitos humanos no mundo". Tais concepções, por sua vez, são reinterpretadas de acordo com cada contexto, apropriadas e redefinidas nos textos constitucionais nacionais, adquirindo contornos variados de acordo com gramáticas políticas e jurídicas locais, relacionadas aos sentidos de justiça em jogo.

No caso brasileiro, quanto à emergência de gramáticas morais, as noções de direitos humanos e respeito às diferenças culturais adquirem um peso importante, exigindo a constituição de formas organizativas muitas vezes estranhas aos modos de vida locais, como, por exemplo, a obrigação de que os grupos constituam uma associação para demandar direitos e recursos, tendo em vista os contornos de um associativismo compulsório e não voluntário (Lobão, 2010). Nesse sentido, consideramos relevante para o artigo a perspectiva da chamada sociologia pragmática francesa, enquanto instrumento metodológico e analítico pertinente. Essa abordagem considera o caráter múltiplo de ação humana para estabelecer relações com o mundo, segundo a qual os indivíduos acionam distintos regimes de justificação (Boltanski; Thévenot, 1991) e de ação (Thévenot, 2006). Assim, para além das diferenças de papel, posição ou lugar social assumido, o que define o comportamento dos indivíduos é uma multiplicidade de possibilidades acionadas pelos os atores nos percursos de suas ações a partir de sua capacidade crítica. Essa diversidade traz, assim, um pluralismo radical com relação ao comportamento humano, onde diferentes lugares, atores e referências são admitidos em uma mesma situação. ${ }^{7}$

Como chama atenção Thévenot (1997), a noção de dignidade assume um lugar central na formulação das diretrizes europeias contemporâneas, que inclui uma gramática de ordem cívica em seu repertório político e moral, para além de normas de caráter exclusivamente econômico, tal como observado com a emergência do mercado comum europeu. Tais projetos abrangentes visam à consolidação dos direitos humanos enquanto um valor universal, bem

7 Entre os principais expoentes da chamada virada pragmática estão Boltanski e Thévenot (1991). Outros autores podem ser pensados como filiados a essa corrente, como Breviglieri e Stavo-Debauge (1999), os quais integravam o Groupe de Sociologie Politique et Morale (GSPM). Na América Latina, diversos pesquisadores se valeram dessa linha em seus estudos: Mota (2014), Freire, J. (2016), Vandenbergue (2006), Nardacchione (2014), Simões (2015). 
como a difusão da ideia segundo a qual o modelo democrático é o mais justo para se viver ${ }^{8}$ (Taylor, 2009).

Esses processos constitucionais de revisão jurídica aportam, por sua vez, níveis de tensão variados e trazem consigo uma dimensão normalizadora e de formalização das categorias que apresenta a relação entre os diferentes atores, sejam eles grupos locais, ONGs, a universidade, os movimentos sociais, entre outros, como permeada pela linguagem das normas, onde se insere a linguagem dos projetos. Assim, destacamos a discussão de Thévenot (1997, p. 215, tradução nossa): "As diretrizes europeias favoreceram grandemente esse deslocamento das resoluções do Estado em favor de procedimentos de regulação, os quais participam de um canal de conformação dita voluntária e que obriga a uma formalização de informação ao longo desse canal certificante."

No caso do referido edital, a publicação se deu no formato de um convite a propostas localizado, ou seja, cujas ações devem ser realizadas exclusivamente no Brasil, ${ }^{9}$ sendo a Delegação da União Europeia no Brasil o órgão contratante. Segundo o documento Orientações aos Requerentes, essa chamada visa a "reforçar a cooperação UE-Brasil em direitos humanos" e "vem de encontro à implementação das diretrizes da UE em matéria de direitos humanos, em âmbito local". O Instrumento Europeu para a Promoção da Democracia e dos Direitos Humanos (IEDDH) é apresentado como o principal dispositivo dentro de um "quadro Estratégico e Plano de Ação da UE para a Democracia e os Direitos Humanos no mundo". Os objetivos (1) gerais e (2) específicos são: (1) "ajudar a sociedade civil a converter-se em uma força efetiva de reforma política e de defesa dos direitos humanos", ao "contribuir para o fortalecimento do papel e da capacidade de diálogo da sociedade civil e dos/as defensores/as de direitos humanos para a promoção dos direitos humanos e a democratização" e (2) para que desempenhem mais eficazmente seu papel enquanto atores relevantes, responsáveis e independentes.

8 É relevante, nesse sentido, que uma das áreas prioritárias definidas pelo edital seja o acompanhamento eleitoral.

9 Segundo o mesmo documento, "os requerentes não brasileiros devem estabelecer parceria com um parceiro local, ou seja, pelo menos um dos co-requerentes deverá ser uma entidade brasileira". 
Nossa proposta se encaixa, assim, em uma das prioridades da chamada:

Apoiar a defesa e proteção dos direitos políticos e civis de Povos Indígenas e/ou de Comunidades Tradicionais (quilombolas, pescadores artesanais, marisqueiros, seringueiros, castanheiros, catadores de coco - dentre outros), ou da População Afrodescendente mediante a renovação e o fortalecimento do papel, dos meios de ação e das capacidades de diálogo político das organizações da sociedade civil e dos/as defensores/as de direitos humanos. ${ }^{10}$

A definição dessas áreas prioritárias, por sua vez, leva em consideração as questões que, no Brasil, são vistas pelo edital como relevantes e que, por isso, exigem o fortalecimento e a defesa dos direitos humanos no país.

É interessante notar que a chamada feita pela Secretaria Especial de Políticas de Promoção da Igualdade Racial (Seppir), órgão do Estado brasileiro, pode ser associada ao fortalecimento das demandas por direitos que, no Brasil, têm nos órgãos estatais interlocutores privilegiados. Como vimos, no caso das comunidades remanescentes de quilombos, institutos como o Incra e a Fundação Cultural Palmares têm papel fundamental no processo de regularização fundiária desses territórios, embora com pesos diferenciados inclusive do ponto de vista formal e administrativo. ${ }^{11}$ No caso do edital da Delegação da União Europeia no Brasil, os mediadores privilegiados são aqueles definidos como organizações não governamentais, entre as quais é elencada a universidade.

A necessidade de efetuar um cadastro na plataforma Pador implica o uso de sua base de dados, a qual abarca uma infinidade de contextos e situações, assim como o espaço onde são cadastrados os diversos editais financiados com os recursos da União Europeia. Nesse caso, ao contrário do edital em questão,

10 As duas outras "prioridades" do edital consistem em "2) Apoiar a defesa e proteção dos direitos políticos e civis da população LGBTI, mediante a renovação e o fortalecimento do papel, dos meios de ação e das capacidades de diálogo político das organizações da sociedade civil e dos/ as defensores/as de direitos humanos" e "3) Apoiar a defesa e proteção dos direitos políticos e civis de populações carcerárias e/ou ex-carcerárias, mediante a renovação e o fortalecimento do papel, dos meios de ação e das capacidades de diálogo político das organizações da sociedade civil e dos/as defensores/as de direitos humanos".

11 Segundo o decreto $\mathrm{n}^{\circ}$ 4.887/2003: “O INCRA deverá regulamentar os procedimentos administrativos para identificação, reconhecimento, delimitação, demarcação e titulação das terras ocupadas pelos remanescentes das comunidades dos quilombos" (Brasil, 2003, art. 3, alínea 1). 
a plataforma Pador contempla situações muito díspares, em diferentes partes do mundo, através do mesmo canal de informação, constituindo uma linguagem relativamente hostil para nós e principalmente para os quilombolas interessados no processo. Muitas dessas normas de informação estão inscritas nas classificações e convenções internacionais acionadas na plataforma.

Essa dinâmica de formalização da informação e de suas implicações políticas, por sua vez, deve ser entendida com relação a outros formatos de informação e aos engajamentos pragmáticos que eles suportam (Thévenot, 1997). A constituição de tecnologia social no diálogo com as lideranças do Sacopã para enviar uma proposta de projeto é, nesse sentido, um processo onde nos inserimos tanto na temporalidade do quilombo quanto na temporalidade das rotinas burocráticas preparadas para receber projetos. Como aponta Thévenot, para formular um projeto é preciso estar equipado para isso, se investir de um projeto, dispor da familiaridade com os instrumentos adequados pra se lançar no projeto. Nesse sentido, é necessário ter uma familiaridade com os equipamentos disponíveis para transitar nesses meios.

Depois da tentativa de envio do projeto para a Seppir em 2013 (Aragon Ovalle, 2014), fomos chamados a preparar projetos com o Sacopã em três outras ocasiões, nos anos de 2014 e 2015. As ONGs costumam assumir um protagonismo no sentido de que estão "preparadas" cotidianamente para a formulação de editais, projetos, etc. A manutenção de sua estrutura física, da disponibilidade de seus funcionários e a própria existência de atividades a serem desempenhadas dependem da legitimidade do Estado para manejar recursos públicos (Ceffaï et al., 2011; Lobão, 2010). Essa dependência permite o engajamento na sustentação das rotinas das ONGs, que frequentemente se distancia da defesa de interesses dos quilombos e outros públicos-alvo.

Os processos de uniformização de uma categoria social como quilombola, população afro-brasileira, entre outras, evidenciam a constituição de porta-vozes qualificados e representantes legítimos de certos grupos. Ultrapassam, assim, a lógica homogeneizante da plataforma Pador, mas, ao mesmo tempo, direcionam sua proposta para organizações previamente equipadas para atender às exigências do processo de inscrição, seleção da documentação, redação do projeto, etc.

O mesmo não acontece em todos os editais formulados pela Delegação da União Europeia no Brasil, o que faz sentido quando pensamos em nossa 
dificuldade de lidar com uma burocracia tão diferente daquela que nos é exigida em agências de fomento estritamente acadêmicas, a saber, a Capes, a Faperj e o CNPq. Assim, tradicionalmente, o "tempo" de produção do conhecimento no âmbito da universidade se define por ser mais demorado, extremamente analítico e pouco prático, enquanto as agências não governamentais e os órgãos do Estado dão respostas e produzem informações, formatadas como diagnósticos imediatos e que, ao mesmo tempo, podem ser vistos como mais superficiais e dificilmente voltados para pensar as suas próprias condições de produção (Miranda; Pita, 2011).

Ao contrário das ONGs, os grupos que poderiam se apresentar ao mesmo tempo como proponentes e público-alvo das propostas, como as comunidades remanescentes de quilombos, adquirem uma familiaridade com as rotinas burocráticas que a elaboração de projetos demanda por meio de uma outra temporalidade, não através de uma rotina profissional. Nesse caso, a solicitação de nosso auxílio seria de suma importância.

A própria discussão em torno da escolha do proponente e do coproponente perpassou meandros burocráticos específicos. Desde o princípio, nossa ideia era que a Associação Cultural Quilombo Sacopã ${ }^{12}$ figurasse como a proponente e o Nufep/UFF como coproponente. Enquanto a ACQS precisou comprovar a posse de um número no Cadastro Geral de Pessoas Jurídicas (CNPJ), segundo as regras do edital, um núcleo de pesquisa não poderia apresentar a proposta, mas apenas a universidade, identificada por meio de um cadastro único. Isso gerou pressa de nossa parte em busca do cadastro da UFF na plataforma Pador, uma vez que o contato do Sacopã foi feito sete dias antes do fechamento do edital.

Mesmo entrando em contato com outros pesquisadores que já tinham acessado a plataforma com o cadastro geral da UFF, não obtivemos a informação. Isso nos obrigou a preencher um cadastro off-line, o qual, mesmo diante de PDFs que tinham um preenchimento controlado, ou seja, limitado de acordo com as expectativas de preenchimento, se transformou numa condição estrutural da plataforma que nos permitiu contornar a burocracia. Essa alternativa

12 A associação foi formada como parte da institucionalização do grupo no contexto do processo de reconhecimento, demarcação e titulação. Tal como consta no decreto $n^{\circ} 4.887 / 2003$ e se manifesta na atuação dos diversos mediadores, a titulação definitiva do território quilombola se dará em nome de uma associação legalmente constituída. 
foi, posteriormente, aceita pela Delegação da União Europeia no Brasil, o que nos mostra a distância entre a plataforma Pador, contratada como plataforma de identificação e divulgação de possíveis entidades proponentes na União Europeia, e o recorte da chamada pública realizada no Brasil. São, portanto, duas formas de socialização necessárias para nos familiarizar e transitar burocraticamente, habilidade que deveria também ser desenvolvida pelos quilombolas, caso quisessem fazer o envio completamente autônomo.

Devemos pontuar, ainda, que a noção de tecnologias sociais, justamente por seu caráter inovador e dinâmico, não foi vista como adequada para a proposta enviada. No parecer da Delegação da União Europeia, que nega o encaminhamento da nossa proposta para a segunda fase da seleção, tivemos uma pontuação máxima ou perto disso no critério "relevância da ação", porém, uma pontuação inferior que nos eliminou da competição no critério "viabilidade da ação".

Dentre os itens sobre a "relevância da ação" destacamos: a "pertinência da proposta em relação aos objetivos e prioridades do convite à apresentação de propostas" (4/5); a "pertinência em relação às necessidades e limitações específicas do(s) país(es) ou da(s) região(ões)-alvo e/ou dos setores relevantes (designadamente, sinergias com outras iniciativas da UE)" e ausência de duplicação (5/5); "a proposta contém elementos de valor acrescentado, tais como, aspectos ambientais, promoção da igualdade de gênero e de oportunidades, necessidades das pessoas com deficiência, direitos das minorias e das populações indígenas, ou inovação e melhores práticas?" (5/5).

Enquanto isso, no critério "viabilidade da ação", recebemos uma pontuação bastante inferior: "a ação foi concebida de forma a assegurar a sua coerência global? Em particular, reflete uma análise dos problemas em causa e tem em conta os fatores externos e os intervenientes relevantes?" (3/5) e "a ação é viável e coerente em relação aos objetivos e resultados esperados?” (3/5). Ainda, o motivo da presente recusa foi dado da seguinte forma: "[o projeto] recebeu uma pontuação inferior à dos candidatos selecionados para a etapa seguinte do concurso".

Assim como colocam Pita e Miranda (2015) quanto a demandas ligadas a direitos humanos na Argentina, vinculadas às instituições supranacionais e demandas de visibilidade internacional, também constatamos uma dificuldade por parte destas instituições de valorizar a produção do conhecimento a partir da produção de dados, o que implica uma hierarquia entre informação e 
conhecimento. O último, necessariamente, é criativo no seu processo de implementação e a expectativa é, justamente, que se aprenda algo com o decorrer da trajetória do projeto, necessariamente afetando seu andamento, seus objetivos, e seu resultado final (Lobão, 2010, Pareschi, 2002). É nesse sentido que essas agências falham em identificar a viabilidade de propostas inovadoras como as tecnologias sociais, ao mesmo tempo em que afirmam buscar e legitimar justamente esse caráter das propostas.

A produção dessas tecnologias, tendo em vista as possibilidades de elaboração de dispositivos simbólicos e institucionais, assim como instrumentos jurídicos, legislativos e administrativos, está articulada a soluções criativas em meio a processos e situações específicas e contextuais. Incluem atividades de assessoria jurídica, aliadas ao conhecimento sobre a produção histórica e social do direito, bem como a participação de pescadores, quilombolas, juristas, antropólogos e políticos, considerando a proposta de um diálogo entre os saberes acadêmicos e os saberes locais, garantindo certa legitimidade política, jurídica e simbólica aos direitos dos grupos minoritários, as quais discutiremos na próxima seção.

\section{Das tecnologias sociais: um caso de apropriação das burocracias voltadas para ONGs}

Com base nos trabalhos vinculados ao Instituto de Estudos Comparados em Administração Institucional de Conflitos (INCT-InEAC) e aos núcleos de pesquisa mencionados, em particular os de Lobão (2010), Mota (2014), Miranda e Pita (2011) e Pita e Miranda (2015), procuramos pensar, ao longo deste artigo, o termo tecnologia social enquanto mecanismo para além da mediação com a burocracia estatal, constituindo a mediação de uma apresentação institucional, de acordo com a linguagem jurídica, que possa ser entendida como construção de direitos nas arenas públicas, sem deixar de notar a heterogeneidade de concepções que podem ser associadas ao termo. Chamamos atenção, ainda, para a possibilidade de construção de uma ética dialógica (Cardoso de Oliveira, R., 2000) entre os conhecimentos elaborados pelos grupos estudados e os compromissos assumidos pelo antropólogo, no âmbito de sua comunidade científica, tendo em vista as possibilidades de construção de direitos nas arenas públicas. 
As tecnologias sociais podem ser pensadas, assim, tanto no âmbito da formulação de políticas de intervenção como na confecção de procedimentos administrativos e jurídicos orientados para o reconhecimento de comunidades remanescentes de quilombos, no Brasil (Ribeiro, 2017). Contrapomos, aqui, programas de intervenção e projetos de transferência de tecnologia que buscam orientar uma mudança de comportamento na definição dos potenciais beneficiários dessas políticas, a partir de planos e concepções preconcebidos a serem aplicados. Nesse sentido, como chamam atenção Vogel e Mello (1989, p. 15):

Talvez seja este um dos mais graves problemas enfrentados pelos programas de intervenção. Ao não tratarem como sujeitos políticos aqueles cuja ação é capaz de influir sobre a sua trajetória, são levados a contabilizar uma série de efeitos não-desejados que, com frequência, superam em muito aqueles alinhados com os objetivos pretendidos.

Assim, mais do que uma preocupação com os efeitos não desejados das políticas de intervenção e dos projetos de transferência de tecnologia, embora esse aspecto seja relevante inclusive para considerar o "sucesso" dos mecanismos de intervenção elaborados, buscamos pensar, nesse sentido, as possibilidades de construção de uma comunidade de argumentação e de uma ética dialógica que tome como relevante os conhecimentos, saberes e interesses dos beneficiários das políticas como legítimos para o próprio desenvolvimento dos processos em curso, considerando a competência das pessoas envolvidas em avaliar e canalizar recursos e dispositivos institucionais e simbólicos para garantir o acesso a bens, serviços, recursos e direitos.

Nesse sentido, as questões levantadas aqui são relativas às possibilidades de construção de uma comunidade de argumentação associada aos processos de construção legal de identidades (Lobão, 2010), enquanto espaços de mediação que contribuem para a construção de tecnologias sociais. Para esse autor:

A materialização de tais Tecnologias Sociais pode ser alcançada com os aportes teóricos de uma corrente que defende que é apenas através da ressignificação compartilhada do objeto da disputa que se alcança a possibilidade de construção de novos instrumentos legais, jurídicos e administrativos que respondam de forma mais adequada aos significados construídos em comum. (Lobão, 2010, p. 15). 
Uma atividade antropológica que nos ajuda a pensar na tecnologia social como uma construção legal de identidades é a confecção do laudo antropológico, quando pensamos nele como um mecanismo que subsidia as demandas de direitos dos grupos, através da produção de um conhecimento que chama atenção para os vínculos de pertencimento social e com o território que habitam. O processo de construção desse conhecimento evidencia a própria relação, sempre conflituosa, entre o tipo de saber produzido pela antropologia e aquele que se destina à elaboração de peças técnicas e à sua leitura por agentes estatais a partir dos paradigmas do direito. ${ }^{13}$ Todavia, a construção de uma tecnologia social não acontece apenas no âmbito internacional ou estatal, mas também dentro de um processo dialógico entre os antropólogos, seus interlocutores e outros agentes que podem estar vinculados ao Estado ou não, seguindo as mais diversas motivações que partem desses dois campos.

Nesse sentido, não é um discurso construído apenas de cima para baixo, ou seja, não é uma expressão de representações que partem daqueles que possuem autoridade etnográfica, silenciando vozes dissonantes. Para usar uma expressão de Johannes Fabian (1990), não é written at os nativos, ou seja, não é um discurso direcionado e imposto a eles, mas written about, ou seja, é um escrito sobre eles. Todo discurso pode ser usado, por um lado, como instrumento de dominação e disciplinarização, ou, por outro, como construção dialógica que, ao invés de silenciar, possibilita a tensão entre presença e representação.

Um texto antropológico nunca poderá, no sentido literal, dar voz ao outro. Isso não é possível pelo mesmo motivo que possibilitava aos colares do kula de Malinowski (1976) agregar o valor continuamente acumulado da tradição. Se trata do fato de que ela é passada de mão em mão, e, como os colares, tem seu valor e significado construído através das pessoas que os carregam. Ao dar mais uma volta pelo arquipélago, os colares não são os mesmos, assim como a voz dos quilombolas já não é apenas a sua voz. É preciso, portanto, entender de onde falamos, enquanto acadêmicos que fazem parte de uma universidade pública, dentro de um país onde as desigualdades sociais, econômicas e de status têm consequências para a autoridade das vozes dessas populações vulneráveis, como são caracterizadas inclusive no edital discutido as populações tradicionais,

13 Essa discussão pode ser encontrada em Kant de Lima e Batista (2014), bem como em O’Dwyer (2010). 
sejam elas pescadores ou quilombolas. Nesse sentido, o presente texto fala de um determinado lugar, em uma determinada época, eticamente consciente de alguns dos usos políticos previsíveis deste discurso (Derrida, 1994), já que o controle pleno das consequências do nosso trabalho é algo impossível.

Essa vulnerabilidade dos quilombolas não é entendida, porém, exclusivamente a partir da noção de tutela dessas populações (Lobão, 2010; Mota, 2014). O diálogo para escrever o projeto e pensar sobre a melhor forma de colocá-lo em prática conta com um esforço para reduzir os efeitos do silenciamento (Barth, 2005), pela ausência de socialização com a burocracia e suas representações legítimas diante do Estado brasileiro (Miranda; Pita, 2011). O trabalho que desenvolvemos, nesse sentido, foi motivado por uma aspiração à simetria, muito embora tenhamos interesses algumas vezes diferentes daqueles dos quilombolas.

Nossas reflexões são fruto do investimento em formação de pesquisadores realizado pelos referidos núcleos de pesquisa da UFF e também parcialmente consequência do retorno aos quilombolas do Sacopã que uma das autoras do presente artigo realizou em 2013. ${ }^{14}$ Durante a fase final de redação de sua dissertação (Aragon Ovalle, 2013), a Seppir havia aberto uma chamada cujo público-alvo eram as comunidades remanescentes de quilombos. Naquele momento nós, pesquisadores do Nufep/UFF, observamos uma série de obstáculos ao protagonismo dessas populações vulneráveis, caso elas mesmas redigissem e enviassem uma proposta, contraditoriamente ao objetivo do próprio edital.

Foram acionados, nessa ocasião, os discursos ouvidos durante os trabalhos de campo: no interior do estado do Rio de Janeiro, onde se localiza a maioria dos quilombos, não há recursos para comunicação entre eles, muito menos para o transporte. As estradas são precárias, os serviços de telefonia fixa não chegam às casas, assim como os serviços de internet e telefones móveis. O projeto se tratava, então, de um calendário de visitas aos quilombos, que guiaria a distribuição de um orçamento que contemplava quilombolas e pesquisadores da UFF.

14 Esse foi um ponto significativo das mediações realizadas através da UFF, as quais incluem, por exemplo, a elaboração do laudo antropológico incorporado posteriormente ao processo de titulação das terras ainda em curso, bem como a aprovação da lei municipal que transforma o Quilombo Sacopã em Área de Especial Interesse Cultural da cidade do Rio de Janeiro, em 2012. 
Em poucas palavras, a execução do projeto era uma via de mão dupla: proporcionava aos nossos interlocutores recursos para exercer o dinamismo que vinha se mostrando importante para o associativismo quilombola (Aragon Ovalle, 2013) e nos colocava numa posição privilegiada para exercer a "participação observante" (Wacquant, 2002), uma vez que estaríamos entranhados em todas as etapas do processo.

Essa reunião, no entanto, não aconteceu imediatamente: conversamos em outubro de 2012 e fomos convidadas a escrever o projeto em janeiro de 2013. Nesse meio tempo, outro edital estava em andamento, fruto da parceria entre essa ONG e alguns quilombos do sul do estado do Rio de Janeiro. A ONG em questão já havia participado de alguns projetos, sempre pegando como contrapartida cerca de metade dos recursos destinados à sua execução. O que já se mostrava um valor alto demais para os serviços prestados se tornou uma situação insustentável quando, no projeto executado no final do ano de 2012, seu desfecho mostrou que $90 \%$ dos recursos não chegaram até os quilombolas.

Essa procura, assim, foi uma iniciativa tomada após os moradores sentirem o insulto moral (Cardoso de Oliveira, L. R., 2002) exercido pela ONG, que demonstrou sua completa falta de comprometimento com as motivações que levavam a classe política de quilombolas do estado do Rio de Janeiro a se envolver num projeto, ao mesmo tempo em que demonstra um investimento de interlocução do grupo com a universidade.

Assim, nesse processo, os pesquisadores são, além de mediadores, coautores e coprotagonistas da construção de estratégias. Contribuímos na constituição de sentidos de justiça, ao romper com a lógica de um planejamento preconcebido e de uma execução sem desvios, que não leva em conta as aspirações, interesses e capacidade crítica dos potenciais beneficiários dessas políticas. Vemos o projeto, portanto, como um encontro, muitas vezes forçado, entre universos simbólicos estruturados em diferentes momentos e locais, e que possuem, justamente por isso, um referencial inalienavelmente dinâmico e local (Lobão, 2010; Pareschi, 2002, 2004).

Diante disso, pensamos que construir os sentidos de justiça sobre a condução da burocracia através de nossas ações e decisões é um processo eminentemente político, onde há a possibilidade de considerar a trajetória dos envolvidos como fonte de direitos para o presente. É possível considerar, assim, o papel social do antropólogo (O’Dwyer, 2002, 2010), notadamente em meio 
aos processos de reconhecimento de comunidades remanescentes de quilombos, mas também com relação a outros contextos de reivindicações de direitos e processos de reconhecimento, como no caso das chamadas populações tradicionais, o que inclui pescadores artesanais, ribeirinhos, extrativistas, grupos indígenas, entre outros, que compõem, por sua vez, uma variedade de situações em termos de formas de acesso ao território e de apropriação dos recursos naturais, bem como em relação aos processos e políticas de intervenção que perpassam a vida de tais grupos. Como chama atenção O'Dwyer (2010, p. 9):

Embora a tradição indigenista e a preocupação dos antropólogos com os direitos dos povos ameríndios tenha marcado significativamente o desenvolvimento da antropologia no Brasil desde os seus primórdios, a Constituição de 1988 ampliou o campo de trabalho fora da academia através da demanda por laudos e estudos ou relatórios antropológicos diversos, com implicações diretas na definição ou na observação dos direitos das minorias. Isso foi especialmente verdade no que concerne à demarcação e ao reconhecimento de territórios indígenas e quilombolas.

Esses contextos permitem considerar o próprio trabalho do antropólogo como tradutor de conhecimentos e experiências locais, tendo em vista a produção de etnografias a serem apresentadas no interior de uma comunidade científica que constrói regras e, mesmo, constrangimentos e formas argumentativas particulares (Kant de lima, 2011). Permite, assim, tornar compreensíveis categorias nativas e saberes locais articuladas aos conceitos e teorias formuladas pelas diferentes linhagens da antropologia, na construção de fatos etnográficos (Peirano, 1992). Consideramos, ainda, a ideia de tradução no sentido que the empresta Latour (1998), a partir da noção de translação, como a possibilidade de deslocamento entre saberes e na conexão de interesses (Freire, L., 2006; Latour, 1998). Busca-se, assim, articular gramáticas e campos de conhecimento distintos que levem em consideração a construção de um diálogo entre saberes para a produção de tecnologias sociais.

Com isso, pensamos o termo tecnologias sociais a partir de acordos possíveis diante das contingências do prazo do edital, dando crédito ao empenho de construir, através da capacidade crítica de todos os envolvidos, um diálogo justo, porque reconhece assimetrias na socialização com a linguagem legítima 
e autorizada pelo Estado e procura conciliar a urgência de entender urgências diante do tempo disponível entre cuidar da família, da saúde, das nossas respectivas pesquisas para construir objetivos e atendê-los.

Não é possível excluir da definição de tecnologias sociais, ainda, a ética dos pesquisadores envolvidos, nem dos quilombolas a serem também contemplados pela proposta do edital, não no sentido de um diálogo puritano, mas no que tange ao nosso entendimento de uma simetria: após mais de dez anos de convivência, pressupomos que ambos os lados conhecem o suficiente sobre o jogo de forças em questão para aceitar participar dele como um todo. Confiamos em nossa capacidade de tecer acordos contextuais e para nos comprometer com o empenho de cumprir nossa parte.

No caso do projeto enviado em 2015 à Delegação da União Europeia no Brasil, o diálogo e o acompanhamento do processo pelos quilombolas, enquanto seus negociadores ativos e seus coautores, envolveu um aprendizado sobre a burocracia bem presente em suas vidas, uma vez que a lógica que sustenta financeiramente as ONGs é a mesma que precisa ser operada por eles para adquirir recursos e status autonomamente. Uma observação interessante é que, uma semana antes do congresso onde apresentamos inicialmente este texto, recebemos a ligação de uma moradora do Sacopã, então envolvida com a burocracia e as representações institucionais do quilombo para concorrer a uma premiação estadual pelo fortalecimento da cultura afro-fluminense, buscando algum auxílio com os documentos a serem levantados e os formulários a serem preenchidos. Qual a alternativa de ajuda, além de outros quilombolas com as mesmas dificuldades, para decifrar a tempo essa linguagem? As ONGs, cujos interesses são impostos tendo como prioridade os gastos e interesses delas próprias, em detrimento dos interesses quilombolas muito além dos problemas possíveis nas relações que estabelecem com a UFF. Esse não é um caso isolado, como demonstram Lobão (2010) e Pareschi (2002, 2004).

Nos perguntamos, diante dessas questões, quem pode ser o proponente, quem é o público-alvo, e quais as categorias para classificá-los. Seriam, como o edital descreve, organizações de jovens e mulheres, ou organizações que representem as populações indígenas de uma maneira geral? A formulação das categorias tem relação com uma dificuldade de classificação ou com uma separação entre grupos historicamente subalternizados (Neves, 2008) e aqueles que podem representar a si mesmos? 
A possibilidade de articular saberes distintos na construção de uma democracia técnica (Callon; Pierre; Yannick, 2001), incluindo nos processos de decisão e na construção de tecnologias sociais o conhecimento produzido por especialistas e por aqueles cujas reivindicações de direitos orientam suas ações nas arenas públicas, por sua vez, não está dissociada das controvérsias e assimetrias nas formas de apresentação e construção do conhecimento.

\section{Considerações finais}

Neste artigo, etnografamos acordos possíveis e contextuais realizados por nós, pesquisadores do Nufep/UFF com os quilombolas do Sacopã, ao longo dos diálogos travados para a confecção de um projeto a ser enviado na ocasião de um edital da Delegação da União Europeia no Brasil. Investimos no desenvolvimento teórico-analítico do termo tecnologia social, no sentido de contemplar a construção de direitos de cidadania das comunidades remanescentes de quilombos no Brasil. Refletimos sobre os diversos atores envolvidos e, notadamente, sobre o lugar da antropologia nas relações estabelecidas entre esses sujeitos de direitos e instâncias estatais e supranacionais.

Procuramos problematizar a familiaridade com vários frutos de socialização que são dados como universais e, nesse sentido, justos. É o caso do domínio do inglês, da familiaridade com a temporalidade de uma rotina burocrática, bem como das formas de apresentação institucionais e burocráticas. Discutimos, nesse sentido, o acesso à burocracia a partir de desigualdades sociais que não são contempladas na formulação do edital, gerando como consequência a transformação de quilombolas que seriam potenciais proponentes em público-alvo.

Isso inclui o estabelecimento de hierarquias e concorrências entre saberes locais e campos de conhecimento disciplinares, mas também com relação às posições institucionais diferenciadas que ocupam as pessoas envolvidas nos processos, tanto os técnicos de agências governamentais como pesquisadores, biólogos, antropólogos, operadores do direito, assim como aqueles que se investem em torno de uma identidade quilombola nas arenas públicas.

Nesse sentido, a chamada pública da Delegação da União Europeia no Brasil é formatada a partir de apresentações institucionais particulares, e delimita 
a autoria de projetos e a problemática a ser abordada na garantia de direitos dos públicos-alvo. Buscamos, nesse sentido, refletir sobre quais papéis são atribuídos aos grupos que são alvo do direcionamento desses recursos, por um lado, e quais papéis são atribuídos às pessoas que devem mobilizar e direcionar esses recursos e, em última instância, viabilizar essa garantia de direitos.

\section{Referências}

ARAGON OVALLE, L. Entre a casa e a política: uma etnografia das controvérsias na ladeira Sacopã. 2013. Dissertação (Mestrado em Antropologia)-Instituto de Ciências Humanas e Filosofia, Universidade Federal Fluminense, Niterói, 2013.

ARAGON OVALLE, L. Entre uma antropologia dos engajamentos e uma antropologia engajada: o lugar das tecnologias sociais nas demandas por direitos do Quilombo Sacopã. In: REUNIÃO BRASILEIRA DE ANTROPOLOGIA, 29., 2014, Natal. Anais..., Brasília: Kiron, 2014.

BARTH, F. Etnicidade e o conceito de cultura. Antropolítica, Niterói, n. 19, p. 15-30, 2. sem. 2005. Tradução: Paulo Gabriel Hilu da Rocha Pinto.

BOLTANSKI, L.; THÉVENOT, L. De la justification: les économies de la grandeur. Paris: Gallimard, 1991.

BRASIL. Ato das Disposições Constitucionais Transitórias. In: BRASIL. Senado Federal. Secretaria Especial de Informática. Constituição da República Federativa do Brasil. Brasília, 1988. p. 40-47. Disponível em: <https://www.senado.gov.br/atividade/const/ con1988/CON1988_05.10.1988/CON1988.pdf>. Acesso em: 19 set. 2015.

BRASIL. Decreto n. 4.887, de 20 de novembro de 2003. Regulamenta o procedimento para identificação, reconhecimento, delimitação, demarcação e titulação das terras ocupadas por remanescentes das comunidades dos quilombos de que trata o art. 68 do Ato das Disposições Constitucionais Transitórias. Brasília, 2003. Disponível em: <http://presrepublica.jusbrasil.com.br/legislacao/98186/decreto-4887-03>. Acesso em: 19 set. 2015.

BREVIGLIERI, M; STAVO-DEBAUGE, J. Le geste pragmatique de la sociologie française. Autour des travaux de Luc Boltanski et Laurent Thévenot. Antropolítica, Niterói, n. 7, p. 7-22, 1999.

CALLON, M.; PIERRE, L.; YANNICK, B. Agir dans un monde incertain. Paris: Seuil, 2001. 
CARDOSO DE OLIVEIRA, L. R. Direito legal e insulto moral: dilemas da cidadania no Brasil, Quebec e EUA. Rio de Janeiro: Relume Dumará, 2002. (Coleção Antropologia da Política).

CARDOSO DE OLIVEIRA, R. Ação indigenista, eticidade e o diálogo interétnico. Estudos Avançados, São Paulo, v. 14, n. 40, p. 213-230, 2000.

CEFAÏ, D. et al. (Org.). Arenas públicas: por uma etnografia da vida associativa. Niterói: Eduff, 2011.

DERRIDA, J. Força de lei. Porto: Campo das Letras, 1994.

FABIAN, J. Presence and representation: the other and anthropological writing. Critical Inquiry, Chicago, v. 16, n. 4, p. 753-772, 1990.

FREIRE, J. Problemas públicos e mobilizações coletivas em Nova Iguaçu. Rio de Janeiro: Garamond, 2016.

FREIRE, L. de L. Seguindo Latour: notas para uma antropologia simétrica. Comum, Rio de Janeiro, v. 11, n. 26, p. 46-65, jan./jun. 2006.

KANT DE LIMA, R. Antropologia da academia: quando os índios somos nós. 3. ed. Niterói: Editora da UFF, 2011.

KANT DE LIMA, R.; BATISTA, B. G. L. Como a Antropologia pode contribuir para a pesquisa jurídica? Um desafio metodológico. Anuário Antropológico, Brasília, n. 1/2014, p. 9-37, 2014.

LATOUR, B. A ciência em ação: como seguir cientistas e engenheiros. São Paulo: Ed. Unesp, 1998.

LEITÃO, L. R. S. Abrindo a "caixa preta" do território: um estudo sociológico sobre a produção de relatórios técnicos de identificação de territórios quilombolas no Rio Grande do Sul. 2006. Dissertação (Mestrado em Sociologia)-Instituto de Filosofia e Ciências Humanas, Universidade Federal do Rio Grande do Sul, Porto Alegre, 2006.

LOBÃO, R. Cosmologias políticas do neocolonialismo: como uma política pública pode se transformar em uma política do ressentimento. Niterói: Editora da UFF, 2010.

MALINOWSKI, B. Os argonautas do Pacífico Ocidental: um relato do empreendimento e da aventura dos nativos nos arquipélagos da Nova Guiné Melanésia. São Paulo: Abril, 1976. (Coleção Os Pensadores).

MIRANDA, A. P. M. de, PITA, M. Rotinas burocráticas e linguagens do estado: políticas de registros estatísticos criminais sobre mortes violentas no Rio de Janeiro e em Buenos Aires. Revista de Sociologia e Política, Curitiba, v. 19, n. 40, p. 59-81, out. 2011. 
MOTA, F. R. Cidadãos em toda parte ou cidadãos à parte?: demandas de direitos e reconhecimento no Brasil e na França. Niterói: Consequência, 2014.

NARDACCHIONE, G. A. En búsqueda de un interlocutor político: entre negociaciones y pruebas de justicia. El conflicto sindical-docente en Argentina (1987-88). Antropolítica, Niterói, n. 37, p. 339-370, 2. sem. 2014.

NEVES, D. P. Mediação social e mediadores políticos. In: NEVES, D. P. (Org.). Desenvolvimento social e mediadores políticos. Porto Alegre: Editora da UFRGS: Programa de Pós-Graduação em Desenvolvimento Rural, 2008.

O'DWYER, E. C. (Org.). Quilombos: identidade étnica e territorialidade. Rio de Janeiro: Editora FGV, 2002.

O'DWYER, E. C. Terras de quilombo: identidade étnica e os caminhos do reconhecimento. Tomo, São Cristóvão, n. 11, p. 43-58, jul./dez. 2007.

O’DWYER, E. C. O papel social do antropólogo: aplicação do fazer antropológico e do conhecimento disciplinar nos debates públicos do Brasil contemporâneo. Rio de Janeiro: E-papers, 2010.

PARESCHI, A. C. C. Desenvolvimento sustentável e pequenos projetos: entre o projetismo, a ideologia e as dinâmicas sociais. 2002. Tese (Doutorado em Antropologia Social)-Instituto de Ciências Sociais, Universidade de Brasília, Brasília, 2002.

PARESCHI, A. C. C. Projetismo e desenvolvimento sustentável: o caso dos pequenos projetos. Hiléia: Revista de Direito Ambiental da Amazônia, Manaus, ano 2, n. 2 , p. 145-197, 2004.

PEIRANO, M. A favor da etnografia. Brasília: Universidade de Brasília, 1992. (Série Antropologia, 130).

PITA, M. V.; MIRANDA, A. P. M. de. Alcance y limitaciones de las consultorías en materia de seguridad pública y derechos humanos. Es posible resistir a las generalizaciones y a los productos estandarizados? - Relato de una experiência. Civitas, Porto Alegre, v. 15, n. 1, p. 128-154, jan./mar. 2015.

RIBEIRO, Y. G. Agentes políticos, especialistas e territórios de direitos: os "remanescentes de quilombo" no Brasil e os "descendentes de imigrantes" na França. 2017. Tese (Doutorado em Antropologia)-Instituto de Ciências Humanas e Filosofia, Universidade Federal Fluminense, Niterói, 2017.

SIMÕES, S. S. A oficina do bem comum: usos e significados da categoria "comunidade" nas arenas públicas cariocas. In: KANT DE LIMA, R.; MELLO, M. A da S.; FREIRE, L. de L. (Org.). Pensando o Rio: políticas públicas, conflitos urbanos e modos de habitar. Niterói: Intertexto, 2015. p. 133-170. 
TAYLOR, C. Multiculturalisme, différence et démocratie. Paris: Flammarion, 2009.

THÉVENOT, L. Un gouvernement par les normes. Pratiques et politiques des formats d'information. In: CONEIN, B.; THÉVENOT, L. (Dir.). Cognition et information en société. Paris: Éditions de l'École des Hautes Études en Sciences Sociales, 1997. p. 205-242.

THÉVENOT, L. L'action au pluriel: sociologie des régimes d'engagement. Paris: La Découverte, 2006.

VANDENBERGUE, F. Construção e crítica na nova sociologia francesa. Sociedade e Estado, Brasília, v. 21, n. 2, p. 315-366, 2006.

VOGEL, A.; MELLO, M. A. da S. O experimento de Tobiki: algumas reflexões sobre a didática magna da prosperidade. Fórum de Educação, Rio de Janeiro, v. 13, n. 1/2, p. 3-25, 1989.

WACQUANT, L. Corpo e alma: notas etnográficas de um aprendiz de boxe. Rio de Janeiro: Relume Dumará, 2002.

Recebido: 31/01/2017 Aceito: 08/08/2017 | Received: 1/31/2017 Accepted: 8/8/2017 